\title{
A Study of Fitting a Swamp Meadow Ecosystem Evapotranspiration to a Model Based on the Penman-Monteith Equation
}

\author{
Feng $\mathrm{Li}^{1,2}$ and Bin Wang ${ }^{2}$ \\ ${ }^{1}$ Management Station of Economic Forestry of Qingyang, 1 West Qingzhou Road, Qingyang 745000, China \\ ${ }^{2}$ College of Life Science and Agriculture and Forestry, Qiqihar University, 23 Wenhua Road, Qiqihar 161006, China \\ Correspondence should be addressed to Bin Wang; wbin03@sina.com
}

Received 17 January 2015; Accepted 26 February 2015

Academic Editor: Wenshan Guo

Copyright (C) 2015 F. Li and B. Wang. This is an open access article distributed under the Creative Commons Attribution License, which permits unrestricted use, distribution, and reproduction in any medium, provided the original work is properly cited.

To accurately estimate the magnitude and seasonal dynamics of evapotranspiration (ET) over an important a swamp meadow in the Fenghuoshan permafrost region, we employed the Food and Agriculture Organization- (FAO-) Penman-Monteith (P-M) model. The model was also used to investigate changes in the crop coefficient $\left(k_{c}\right)$, which was calculated as the ratio of the measured actual $\mathrm{ET}$ ( $\mathrm{ET}_{a}$ from the eddy covariance (EC) system) to the reference ET ( $\mathrm{ET}_{0}$ from the P-M model). The results indicated a reference ET of $900 \mathrm{~mm}$ /year from the swamp meadow ecosystem, which was significantly higher than the actual ET (426 mm/year). The reference ET peaked from April to July, while the actual ET was primarily in growing season. The value of $k_{c}$ exhibited significant seasonal variations within the range $0.3-1.0$ with a mean $k_{c}$ of 0.55 during the growing season. The daily $k_{c}$ showed a linear increase with $R_{n}$ and $T_{a}$ and a linear decrease with the VPD. With respect to the biotic factors, the biomass exhibited a significant positive correlation with $k_{c}$. Thus, a daily $k_{c}$ model is developed as a function of the VPD, $R_{n}, T_{a}$, and biomass.

\section{Introduction}

The hydrologic balance of terrestrial ecosystems is an important determinant of ecosystem structure, function, and productivity [1]. Evapotranspiration (ET), which is the second largest water flux in the terrestrial hydrologic cycle, plays an important role in the maintenance of the water and energy balance of the ground surface [2]. In addition, ET processes are closely related to vegetation conditions, the ecophysiological processes of plants, soil environments, and micrometeorological characteristics. Thus, ET is a pivotal water exchange process in the soil-plant-atmosphere continuum (SPAC). Therefore, accurate ET estimation is significant not only to the regulation and management of hydrologic cycles in ecosystems but also to scientific decisions regarding local ecological construction and production activities in agriculture and animal husbandry [3-5].

Domestic and international scholars have investigated land surface ET for more than 200 years and have developed a number of fitting models and observational methods for ecosystem evapotranspiration [6-9]. Currently, the eddy covariance (EC) system is the most extensively used and sophisticated micrometeorological approach. Ecosystem ET may be continuously monitored with the EC system without damage to the soil or vegetation. The Penman equation, which utilizes conventional meteorological data, is the most influential fitting equation for predicting ET. This equation was proposed in 1948 when Penman proposed a formula for calculating ET from a water surface, which considers radiant energy, air saturation deficit, wind speed, and other ETinfluencing factors. Based on prior research, Monteith and Unsworth modified the Penman equation and proposed the Penman-Monteith (P-M) model, which is a canopy ET model that has been extensively applied [7]. In 1990s, the Food and Agriculture Organization (FAO) of the United Nations amended the P-M model for the estimation of actual ET from farmland and grassland and recommended this modified model as a standard method for calculating ET [10].

In the P-M model recommended by the FAO (the FAO$\mathrm{P}-\mathrm{M}$ model), a crop coefficient $\left(k_{c}\right)$ has been introduced to 
correct reference ET values and to accurately estimate actual ET values in specific ecosystems. Studies have reported that $k_{c}$ is related to various biotic factors, such as crop type and growth stage $[5,11]$. For homogeneous vegetation, which consists of plants in a particular growth stage, $k_{c}$ may be regarded as a constant. For example, in the FAO-56 method, $k_{c}$ values are assigned based on a meadow's growth stage; thus, $k_{c}$ values for the initial, mid, and late season growth stages are $0.4,1.05$, and 0.85 , respectively [10]. Recent studies have demonstrated that $k_{c}$ exhibits specific variations and is affected by radiant energy, moisture levels, and other environmental factors $[12,13]$. The $k_{c}$ value is the key to using the FAO-P-M model to accurately estimate the actual ET of an ecosystem. Thus, the study of the patterns and characteristics of changes in $k_{c}$ in natural meadowland can improve the accuracy and simplicity of the calculation of the ecological water demand of meadowlands and provide a theoretical foundation for the grazing production of these lands.

The Sanjiangyuan Region (i.e., the source of the Yangtze, Yellow, and Mekong rivers, well known as the "water tower of Asia") is located in the hinterlands of the Qinghai-Tibet Plateau, which plays a pivotal role in the global hydrologic cycle and the global water balance. Swamp meadow ecosystem, which is one of the most extensively distributed types of vegetation in the Sanjiangyuan Region, covers an area of approximately $127.63 \mathrm{~km}^{2}$ [14]. The swamp meadow is also a unique natural landscape and one of the most important grassland resources for grazing [15]. Few studies have explored the ET characteristics of meadow ecosystems [16]; as a result, studies on applicable models for accurately and conveniently evaluating ET in the swamp meadow ecosystem also remain scarce.

This study aimed to achieve the following objectives: (1) use the FAO-P-M model and eddy covariance system to explore the dynamics of the actual ET and reference ET changes in the swamp meadow ecosystem of the Sanjiangyuan Region and (2) derive a suitable $k_{c}$-based model of the swamp meadow ecosystem by determining how $k_{c}$ values vary with changes in meadow climate and vegetation and by establishing the relationships between $k_{c}$ and the factors (including both the environmental and biotic factors).

\section{Material and Methods}

2.1. Study Site. The Fenghuoshan permafrost region of the Sanjiangyuan Region $\left(92^{\circ} 50^{\prime}-93^{\circ} 3^{\prime} \mathrm{E}\right.$ and $\left.34^{\circ} 40^{\prime}-34^{\circ} 48^{\prime} \mathrm{N}\right)$, located in the upper watershed of the Zuomo Xikong River, a tributary of the Yangtze River, with typical swamp meadow ecosystem, was chosen as the system of the study. The region covers a total area of $127.63 \mathrm{~km}^{2}$ at elevations ranging from 4680 to $5360 \mathrm{~m}$, belonging to an arid climate area and without glacial or multiyear snowpack. The mean annual (1973 to 2005) air temperature, the highest air temperature, the lowest air temperature, precipitation, evaporation, and relative humidity are $-5.2^{\circ} \mathrm{C}, 23.2^{\circ} \mathrm{C},-37.7^{\circ} \mathrm{C}, 290.9 \mathrm{~mm}$, $1316.9 \mathrm{~mm}$, and $57 \%$, respectively. The mean annual ground temperature ranges from $-1.5^{\circ} \mathrm{C}$ to $4.0^{\circ} \mathrm{C}$ and the main frozen soil depth ranges from $50 \mathrm{~m}$ to $120 \mathrm{~m}$. The permafrost table varies between 0.8 and $2.5 \mathrm{~m}$ depth. The average annual duration of sunshine is $2462.7 \mathrm{~h}$, and the total radiation $\left(R_{s}\right)$ received per year ranges from 6000 to $7000 \mathrm{MJ} \mathrm{m}^{-2}$. The swamp meadow features high vegetation cover composed of short and densely distributed plants.

The vegetation primarily consists of meadow species, such as Stipa aliena, Kobresia tibetica, Festuca sp., Carex atrofusca, Leontopodium leontopetaloides, and other alpine plants. The meadow land, which is primarily used for meadow (January to May and September to December), serves as an important grazing resource in the plateau region. The aboveground biomass of the swamp meadow increases in early May and peaks in August, with a multiyear average biomass of approximately $350 \mathrm{~g} / \mathrm{m}^{2}$. The study area receives a yearly precipitation of approximately $600 \mathrm{~mm}$. This precipitation is primarily concentrated between May and September, and changes in the soil water content (SWC) are subject to precipitation-related effects.

\subsection{Measurements}

2.2.1. Flux Measurements. EC observation system was placed in the center of the study area. This area features flat terrain, which enables unobscured observation and provides a sufficiently large "fetch" to satisfy the required physical conditions for eddy and meteorological observations. ET was measured using a $\mathrm{H}_{2} \mathrm{O} / \mathrm{CO}_{2}$ infrared gas analyzer (Li-7500, Li-Cor, USA) and a three-dimensional sonic anemometer (CSAT3, CSI, USA) with a sensor placed $2.2 \mathrm{~m}$ above the ground. A data logger (CR5000, Campbell Inc.) was employed to continuously record water vapor flux data and output average values at $15 \mathrm{~min}$ intervals. The actual ET $\left(\mathrm{ET}_{a}\right)$ was measured by the EC system in this study.

2.2.2. Meteorological Measurements. Environmental variables were continuously measured at this site. Air temperature $\left(T_{a}\right)$, humidity, and actual vapor pressures were measured at $110 \mathrm{~cm}$ and $220 \mathrm{~cm}$ (HMP45C, CSI); soil temperature was measured at $0,5,10,20,30$, and $50 \mathrm{~cm}$ depths (thermocouple); solar radiation $\left(R_{s}\right)$ and net radiation $\left(R_{n}\right)$ were measured at $150 \mathrm{~cm}$ (CNR-1, Kipp and Zonen, Netherlands); a horizontal wind-speed sensor (014A and 034A-L, CSI) was attached at $110 \mathrm{~cm}$ and $220 \mathrm{~cm}$ to measure horizontal wind speeds; precipitation was measured at $70 \mathrm{~cm}$ (TE525MM, CSI); SWC was measured at 5, 20, and $50 \mathrm{~cm}$ depths (TDR soil moisture sensor; CS615, CSI); and the soil heat flux was set at a depth of $2 \mathrm{~cm}$ (HFT-3, CSI). The signals were sampled at $10 \mathrm{~Hz}$, and $15 \mathrm{~min}$ mean data were logged by the data logger (CR23X, CSI).

2.2.3. Observations of Vegetation Data. Aboveground biomass in the study area was measured semimonthly during the growing season. A harvesting method was adopted to obtain these measurements. In particular, five $0.5 \mathrm{~m} \times 0.5 \mathrm{~m}$ quadrants were randomly selected; within each quadrant, plants were harvested by cutting the plants at ground level and loading the plants into sampling bags. Each sample was numbered, rapidly transported to a laboratory, and dried at 
$65^{\circ} \mathrm{C}$ until a constant weight was obtained for each sample. These weights were subsequently converted into $\mathrm{g} / \mathrm{m}^{2}$.

\subsection{The FAO-P-M Model}

2.3.1. The Calculation of Reference ET. The reference crop comprises a well-managed short grass of uniform height (8$15 \mathrm{~cm}$ ) that completely covers the ground and grows lushly across open ground without experiencing water stress. The reference crop ET refers to the ET of the reference crop under these conditions [10]. In this study, the standardized FAO-P$M$ model was used to calculate the actual ET in the swamp meadow ecosystem. This model includes two componentsreference ET and $k_{c}$-as indicated in the following equation:

$$
\mathrm{ET}_{\mathrm{P} \_\mathrm{M}}=k_{c} \mathrm{ET}_{0} \text {. }
$$

In this equation, $\mathrm{ET}_{\mathrm{P} \_\mathrm{M}}$ is the actual $\mathrm{ET}$ of an ecosystem in the FAO-P-M model, $k_{c}$ is the crop coefficient, and $\mathrm{ET}_{0}$ is the reference ET. The reference surface consists of well-watered grass with a height of $12 \mathrm{~cm}$ and a fixed surface resistance of $70 \mathrm{~s} / \mathrm{m}$. The applicable equation is expressed as

$$
\mathrm{ET}_{0}=\frac{0.408 \Delta\left(R_{n}-G\right)+\gamma(900 /(T+273)) u\left(e_{s}-e_{a}\right)}{\Delta+\gamma(1+0.34 u)},
$$

where $\Delta$ is the slope of the saturation vapor pressure curve at the examined temperature; $R_{n}$ is the net radiation; $G$ is the soil heat flux; $\gamma$ is the psychrometric constant; $T$ is the mean daily temperature at a height of $2 \mathrm{~m}$; $u$ is the wind speed at a height of $2 \mathrm{~m}$; and $e_{s}$ and $e_{a}$ are the saturation vapor pressure and actual vapor pressure, respectively. $\Delta$ and $\gamma$ are calculated as

$$
\begin{gathered}
\Delta=\frac{4098 \cdot\{0.6108 \exp [17.27 T /(T+237.3)]\}}{(T+237.3)^{2}}, \\
\gamma=\frac{c_{p} \cdot P}{0.622 \lambda}, \\
\lambda=2.501-\left(2.361 \times 10^{-3}\right) \cdot T,
\end{gathered}
$$

where $c_{p}$ is the specific heat at constant pressure, which has a fixed value of $1.013 \times 10^{-3} \mathrm{MJ} / \mathrm{kg}^{\circ} \mathrm{C}$; $P$ is the atmospheric pressure; 0.662 is the ratio of the molecular weight of water vapor to the molecular weight of dry air; and $\lambda$ is the latent heat of vaporization, which represents the energy per unit volume of water required to convert water into steam under ambient temperature and pressure conditions. The study meadow area is located on a plateau zone at an average elevation of $3250 \mathrm{~m}$. Using (4), the atmospheric pressure $(P)$ can be calculated from this average elevation $(H=3250 \mathrm{~m})$ :

$$
P=1013-0.1093 H \text {. }
$$

2.3.2. The Crop Coefficient $\left(k_{c}\right)$. The crop coefficient $k_{c}$ was obtained from the ratio of the reference ET in 2004 to the ET obtained from EC system observations in 2004 and fitted with environmental factors to obtain an empirical equation, which was eventually validated by 2005 data. In the FAO56 approach, the growth of meadow plants was divided into different growth stages [10]. The study area of the current investigation features an alpine climate; in this area, plant growth typically begins in late April, and the growing season extends from May to September.

2.4. Evaluation Methods. In this study, the slope, linear correlation coefficient $\left(R^{2}\right)$, relative root-mean-squared error (RRMSE), index of agreement (IA), and coefficient of determination (CD) were utilized to examine the extent of the differences between the observed and calculated values of ET and to statistically analyze the accuracy of the adopted fitting approach from multiple perspectives. The slope and $R^{2}$ were calculated by Origin 8.0. RRMSE, IA, and CD values were computed as $[13,17]$

$$
\begin{gathered}
\mathrm{RRMSE}=\sqrt{\frac{\sum_{i=1}^{n}\left(O_{i}-E_{i}\right)^{2}}{n}} \cdot \frac{1}{\bar{O}} \\
\mathrm{IA}=1-\frac{\sum_{i=1}^{n}\left(E_{i}-O_{i}\right)^{2}}{\sum_{i=1}^{n}\left(\left|E_{i}-\bar{O}\right|+\left|O_{i}-\bar{O}\right|\right)^{2}} \\
\mathrm{CD}=\frac{\sum_{i=1}^{n}\left(O_{i}-\bar{O}\right)^{2}}{\sum_{i=1}^{n}\left(E_{i}-\bar{O}\right)^{2}},
\end{gathered}
$$

where $O_{i}$ indicates the $i$ th observed value, $E_{i}$ represents the $i$ th simulated or estimated value, $n$ represents the number of samples, and $O$ is the mean observed value. RRMSE is a measure of the relative magnitude of residuals; smaller values of RRMSE indicate better model calculation results. The IA can be used to evaluate the correlation between the observed values and the simulated values; the closer the IA is to 1, the more closely the fitted values match the observed values. The $\mathrm{CD}$ can be used to measure the dispersion of the simulated values from the mean observed values; a CD greater than 0.8 indicates satisfactory simulation results [18].

\section{Results and Discussion}

3.1. Seasonal Variations in Reference ET (ET $)$ and Actual ET. As indicated in Figure 1, the reference ET derived from the P-M model was significantly higher than the actual ET measured by the EC system. The reference ET $\left(\mathrm{ET}_{0}\right)$ refers to the reference capacity of moisture diffusion from the ecosystem to the atmosphere under specific environmental conditions; thus, $\mathrm{ET}_{0}$ represents the maximum ET. The annual reference ET of the examined swamp meadow was $900.2 \mathrm{~mm}$, which was significantly higher than the actual ET of $425.8 \mathrm{~mm}$. These parameters also exhibited significant seasonal variations. $\mathrm{ET}_{0}$ began to significantly increase in March and attained peak levels from April to July; however, it began to decline in August. The total $\mathrm{ET}_{0}$ during the growing season (from May to September) was $487.1 \mathrm{~mm}$, which represented $54 \%$ of the annual cumulative $\mathrm{ET}_{0}$. Conversely, seasonal variations in actual ET $\left(\mathrm{ET}_{a}\right)$ in the swamp meadow lagged behind variations in reference ET. The $\mathrm{ET}_{a}$ 


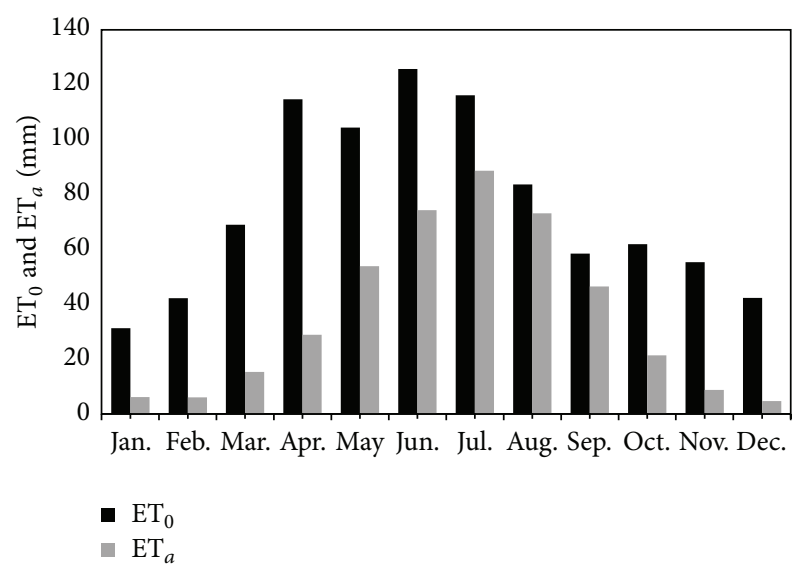

FIgure 1: Annual variations in reference ET $\left(\mathrm{ET}_{0}\right)$ and actual ET $\left(\mathrm{ET}_{a}\right)$.

was concentrated in the growing season; between May and September the $\mathrm{ET}_{a}$ was $337.1 \mathrm{~mm}$, which represented $79 \%$ of the annual cumulative $\mathrm{ET}_{a}$.

According to its definition, the reference ET $\left(\mathrm{ET}_{0}\right)$ was only affected by climatic parameters [10]. As shown in (2), the net radiation $\left(R_{n}\right)$, vapor pressure deficit $\left(\mathrm{VPD}, e_{s}-e_{a}\right)$, air temperature $\left(T_{a}\right)$, and wind speed $(u)$ determined the reference ET. The annual variation of these environmental factors was shown in Figure 2. As the maximum of $R_{n}, \mathrm{VPD}$, and $u$ occurred during April to June (Figure 2), $\mathrm{ET}_{0}$ reached its maximum value at a similar period (March to June). However, with the canopy development in growing season, the effect of biotic factors will exert increasing influence on the actual ET. Therefore, with the $\mathrm{ET}_{a}$ rapidly increasing in growing season, the difference between $\mathrm{ET}_{0}$ and $\mathrm{ET}_{a}$ became smaller (Figure 1).

Moreover, the reference ET in growing season $(487.1 \mathrm{~mm})$ was lower than the value of precipitation $(579.7 \mathrm{~mm})$. The ratio of $\mathrm{ET}_{0}$ to $P$ was $84 \%$ during growing season. This result was similar to a nonirrigated pasture [19]; however, it was much lower than some grassland ecosystems $[9,20]$. In these grasslands, the reference ET was significantly higher than the precipitation in growing season.

Comparing to these grasslands $[9,20]$, the lower $\mathrm{ET}_{0}$ may be caused by the unique climate in this plateau. The net radiation $\left(R_{n}\right)$ in the Qinghai-Tibetan Plateau was much lower than that for lowland grasslands [21], despite the high incident solar radiation $\left(R_{s}\right)$, due to the fact that the net longwave radiation in alpine region is much higher than that for lowland regions [22]. In this swamp meadow, the $R_{n}$ was much lower than the $R_{s}$, and the average $R_{n}$ and $R_{s}$ values were 7.7 and $16.6 \mathrm{~mol} /\left(\mathrm{m}^{2} \mathrm{~d}\right.$ ), respectively (Figure $2(\mathrm{a})$ ). The low energy available for water evaporation may limit the reference ET to some extent. Moreover, VPD and $T_{a}$ were meteorological variables for control of water vapour exchange between the atmosphere and vegetation [23]. Gu et al. [24] indicated that low VPD and $T_{a}$ due to the frequent precipitation and the altitude were characteristics of the climate in the swamp meadow in Northeast Qinghai-Tibetan Plateau. Figure 2(b) showed the variation of VPD and $T_{a}$ in this study site. The maximum values of daily mean VPD and $T_{a}$ were only $1.5 \mathrm{kPa}$ and $14.5^{\circ} \mathrm{C}$, which were greatly lower than many other grasslands with the maximum VPD ranging from about 2 to $5 \mathrm{kPa}$ and with the maximum $T_{a}$ ranging from about 20 to $30^{\circ} \mathrm{C}$ [25-27]. The low VPD and $T_{a}$ might imply the weak driving power and are considered as the factors to restrict the reference ET in growing season.

3.2. The Seasonal Variation in $k_{c}$. Due to the difference between reference ET and actual ET, the correct determination of $k_{c}$, which is the ratio of daily $\mathrm{ET}$ to $\mathrm{ET}_{0}$, is important for the accurate estimation of the actual ET. In this study, $k_{c}$ exhibited a gradual rise from mid-April to mid-June and remained at a high level in July and August (Figure 3). The value of $k_{c}$ rapidly declined in September and was less than 0.2 by the end of October. During the growing season, which extended from May to September, $k_{c}$ exhibited a mean value of 0.55 and fluctuated within the range of $0.30-0.92$. This range is consistent with the range of $k_{c}$ values reported in FAO-56 (0.30-1.05) [10] but is significantly higher than the range of $k_{c}$ values observed for a typical steppe $(0.32-0.68)$ [28] and temperate desert steppe (0.02-0.50) [13] of Inner Mongolia. These results indicated that the $k_{c}$ for the swamp meadow features more adequate moisture and better plant growth conditions than arid and semiarid steppe ecosystems.

\subsection{Factors That Impact $k_{c}$}

3.3.1. The Effect of Environmental Factors on $k_{c}$. Previous studies have focused on $k_{c}$ values related to local climate conditions $[12,13]$. In this meadow, the Pearson productmoment correlation coefficients for the relationships between $k_{c}$ and its main environmental factors were computed on a daily scale (Table 1 ). This computation showed that the VPD and $R_{n}$ were critical for controlling $k_{c}$. $T_{a}$ also showed a significant relation to $k_{c}$, whereas $u$ and SWC at a depth of $5 \mathrm{~cm}$ were not significant at the $95 \%$ confidence level.

The responses of $k_{c}$ to changes in VPD, $R_{n}$, and $T_{a}$ are illustrated in Figure 4. To reduce or offset the errors associated with the $k_{c}$ values, VPD, $R_{n}$, and $T_{a}$ were grouped into bins with the following criteria: $0.2 \mathrm{kPa}$ for VPD, $1 \mathrm{MJ} / \mathrm{m}^{2} \mathrm{~d}$ for $R_{n}$, and $2^{\circ} \mathrm{C}$ for $T_{a} \cdot k_{c}$ increased linearly in response to an increase in $R_{n}$ and $T_{a}$ and in response to a decrease in VPD (Figure 4). L. Zhou and G. S. Zhou [29] also obtained a similar result from a study of a reed marsh. However, our result was different from a study in a temperate desert steppe [13], which demonstrated that the soil water content (SWC) was the most important factor for determining $k_{c}$. In this study, the root-layer $(0-10 \mathrm{~cm})$ SWC fluctuated within the range $0.2-0.6 \mathrm{~m}^{3} / \mathrm{m}^{3}$ (Figure $1(\mathrm{c})$ ), which was much better than the SWC at desert steppe in Inner Mongolia $\left(0.05-0.15 \mathrm{~m}^{3} / \mathrm{m}^{3}\right)$. The higher soil moist in this swamp meadow might weaken the SWC impact on $k_{c}$.

Daily $k_{c}$ for the swamp meadow can be expressed by an empirical equation from the correlation and regression analyses of the relationships between $k_{c}$ and its statistically significant environmental variables:

$$
k_{c}=0.597-0.801 \mathrm{VPD}+0.026 R_{n}+0.040 T_{a} .
$$




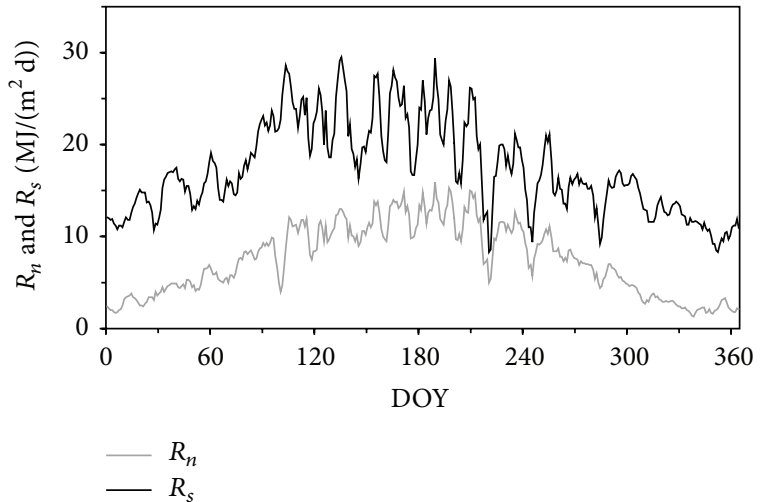

(a)

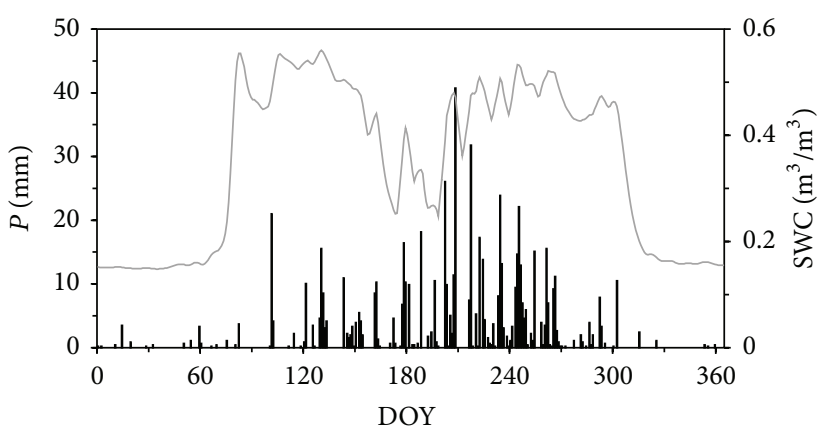

$P$
- SWC

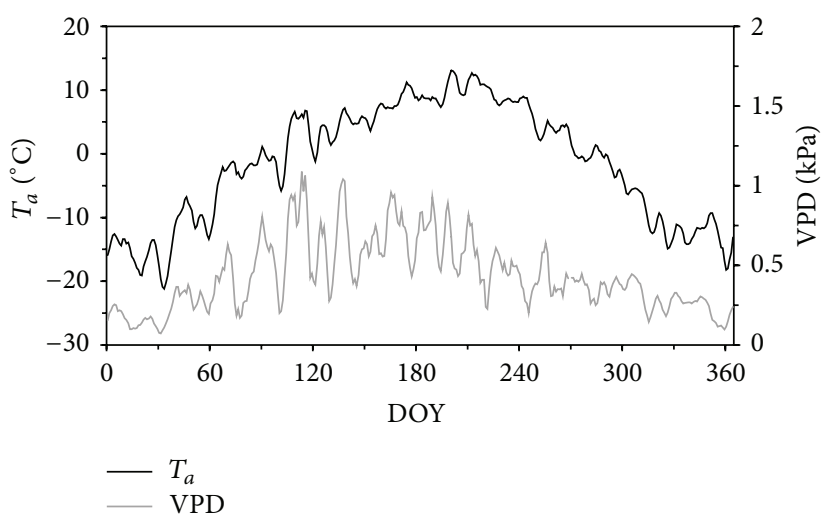

(b)

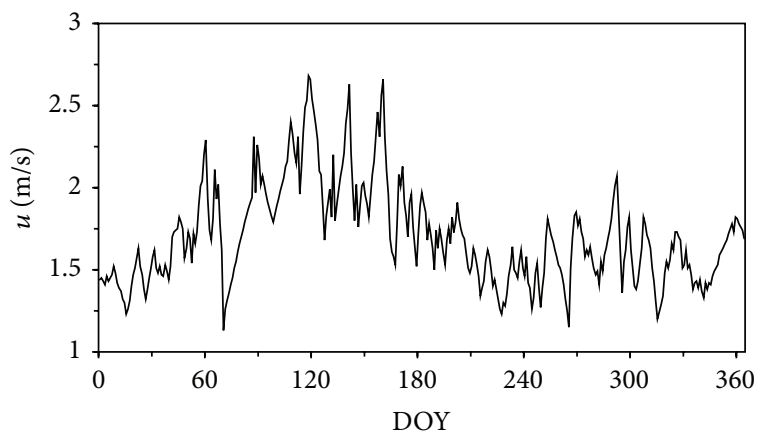

(d)

FIGURE 2: Temporal variations of (a) net radiation $\left(R_{n}\right)$ and solar radiation $\left(R_{s}\right)$, (b) daily mean air temperature $\left(T_{a}\right)$ and vapor pressure deficit (VPD), (c) daily precipitation $(P)$ and soil water content at $5 \mathrm{~cm}$ depth (SWC), and (d) wind speed $(u)$ in the swamp meadow during 2004.

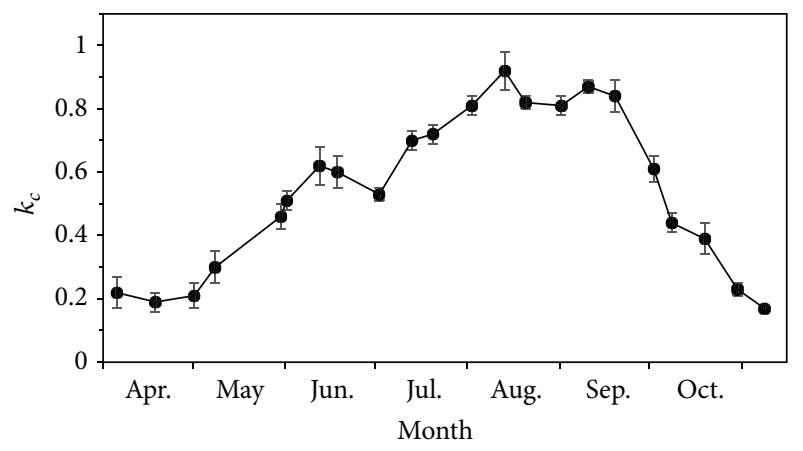

FIGURE 3: Seasonal variation in the $k_{c}$.

3.3.2. The Effects of Biotic Factors on $k_{c}$. In addition to environmental factors, the plant species composition, growth conditions, and other biotic factors can significantly affect $k_{c}[3,30,31]$. Biomass directly reflects the growth status of a biological community. In this study, the sampled plants began to grow at the end of April, which caused an increase in the biomass that primarily began in early May. The biomass rapidly increased during June and August and attained a peak in late August (with a maximum value of $353.1 \mathrm{~g} / \mathrm{m}^{2}$ in the study year). After August, the biomass rapidly declined as plants gradually died (Figure 5(a)). The linear regression analysis of the relationship between $k_{c}$ and the biomass demonstrated a significant positive correlation between $k_{c}$ and the biomass; however, the significance of this correlation changed during different growth stages. As indicated in Figure 5(b), the biomass increased and $k_{c}$ rapidly increased from 0.45 to 0.93 from May to middle August. After biomass attained its peak, $k_{c}$ began to decline and decreased to 0.39 in late October, while no significant decrease in $k_{c}$ was observed from September to October, because $k_{c}$ only decreased from 0.54 to 0.39 during this period.

The following linear equations describe how $k_{c}$ increases with biomass:

May-Middle August: $k_{c}=0.0019 \times$ biomass +0.4521 ,

Middle August-Oct: $k_{c}=0.0008 \times$ biomass +0.2514 .

Considering both biotic and environmental factors, daily actual ET can be calculated as follows:

May-Middle August:

$$
\begin{aligned}
\mathrm{ET}= & \left(0.597-0.801 \mathrm{VPD}+0.026 R_{n}+0.040 T_{a}\right) \\
& \cdot(0.0019 \text { biomass }+0.4521) \times \mathrm{ET}_{0}
\end{aligned}
$$


TABLE 1: Pearson product-moment correlation coefficients for the relationships between daily $k_{c}$ and daily average values for environmental variables: SWC at a depth of $5 \mathrm{~cm}$, atmospheric VPD, wind speed $(u), R_{n}$, and $T_{a}$ over the swamp meadow on a daily basis for days without rain during the 2004 growing season $(n=106)$.

\begin{tabular}{lccccc}
\hline & $k_{c}$ & SWC & VPD & $u$ & $R_{n}$ \\
\hline$k_{c}$ & 1.000 & & & & \\
SWC & -0.168 & 1.000 & & & \\
VPD & $-0.509^{* *}$ & $-0.324^{*}$ & 1.000 & & \\
$u$ & -0.175 & $0.339^{*}$ & -0.114 & 1.000 & \\
$R_{n}$ & $0.442^{* *}$ & $-0.440^{* *}$ & 0.164 & $-0.309^{*}$ & 1.000 \\
$T_{a}$ & $0.402^{*}$ & $-0.590^{* *}$ & $0.400^{*}$ & $-0.518^{* *}$ & $0.429^{* *}$ \\
\hline
\end{tabular}

${ }^{*}$ Correlation coefficient at 0.05 significant level.

${ }^{* *}$ Correlation coefficient at 0.01 significant level.

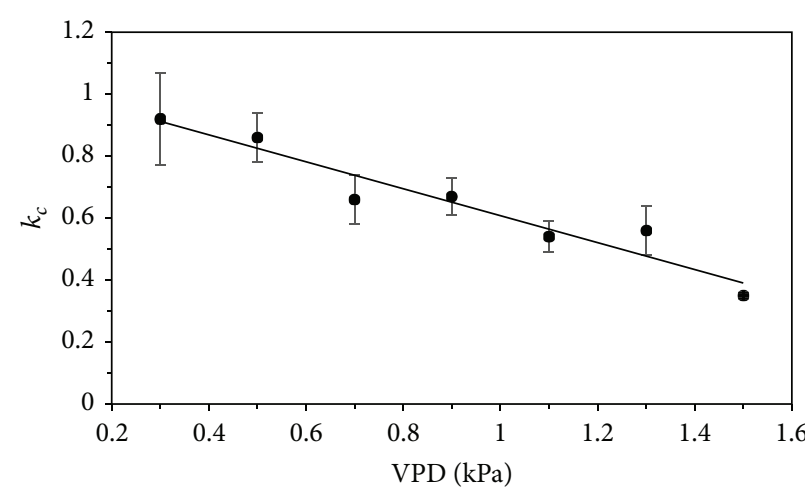

(a)

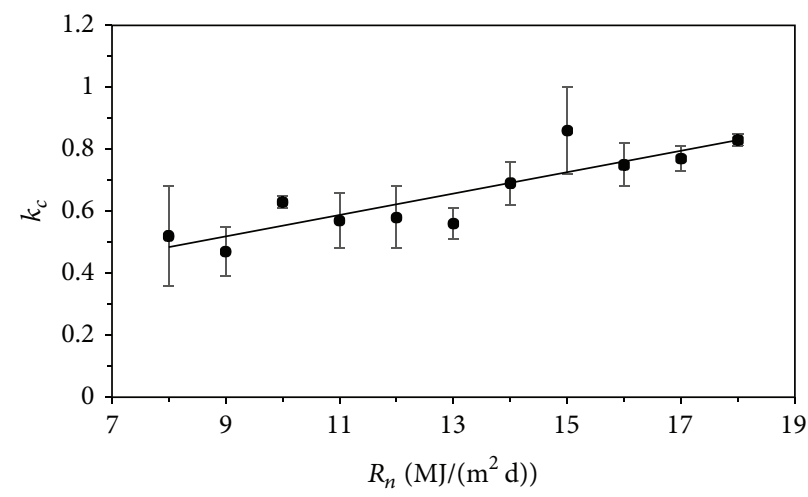

(b)

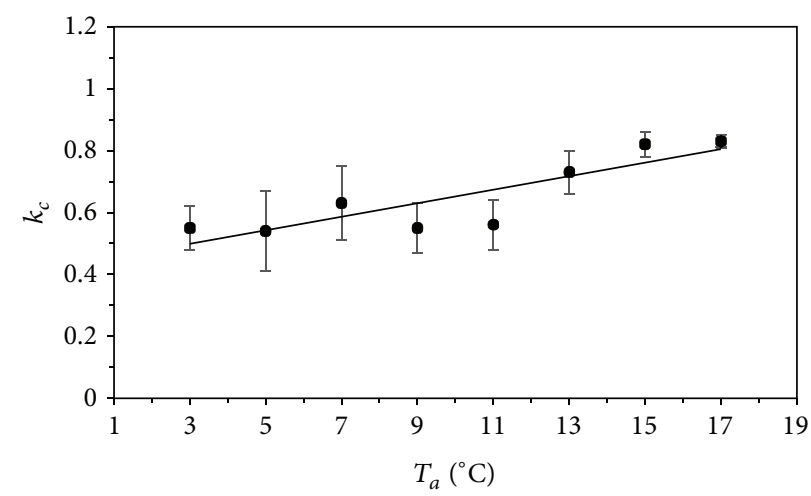

(c)

Figure 4: Linear response of $k_{c}$ to (a) VPD, (b) $R_{n}$, and (c) $T_{a}$. The daily $k_{c}$ data were averaged with a bin width of $0.2 \mathrm{kPa}$ for VPD, $1 \mathrm{MJ} /\left(\mathrm{m}^{2} \mathrm{~d}\right)$ for $R_{n}$, and $2^{\circ} \mathrm{C}$ for $T_{a}$, respectively. Bars indicate mean $\pm \mathrm{SD}$.

Middle August-Oct:

$$
\begin{aligned}
\mathrm{ET}= & \left(0.597-0.801 \mathrm{VPD}+0.026 R_{n}+0.040 T_{a}\right) \\
& \cdot(0.0008 \text { biomass }+0.2514) \times \mathrm{ET}_{0} .
\end{aligned}
$$

3.4. Test for Modeling Evapotranspiration. Equation (9) was validated using the EC data collected during the 2005 growing season. The model performed well during the growing season. The simulated daily ET $\left(\mathrm{ET}_{\mathrm{mod}}\right)$ followed the seasonal trend of the EC measured ET $\left(\mathrm{ET}_{a}\right)$ (Figure 6). The slope $(=0.95)$ of the regression line between the measured and simulated ET passes through the origin close to 1 , with $R^{2}=$ 0.76 , a RRMSE of $0.23 \mathrm{~mm} / \mathrm{d}$, and an IA of 0.92 .

In this study, the abiotic and biotic factors enabled a better estimation of evapotranspiration. In Table 2, the slope, $R^{2}$, IA, and CD of $\mathrm{ET}_{\bmod 1}$ are greater and the RRMES is

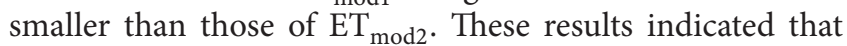
relative to the fitting method that accounts for meteorological variables, the fitting method that comprehensively considers meteorological factors and vegetation conditions can be used to derive simulated ET results that are closer to the actual observed ET results (Table 2). 


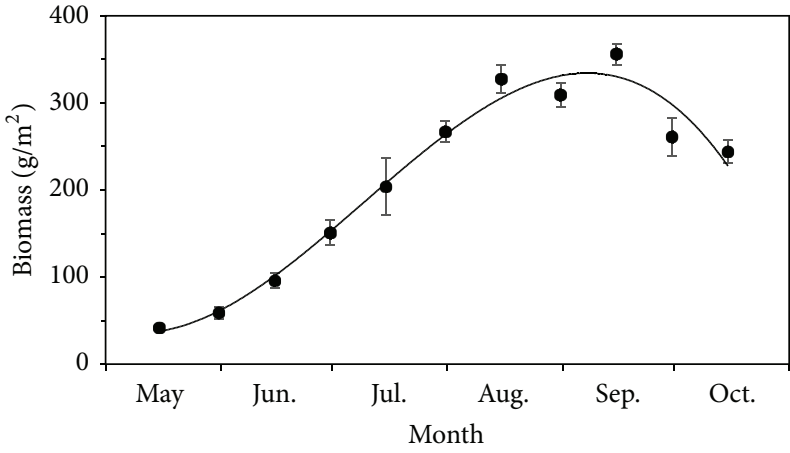

(a)

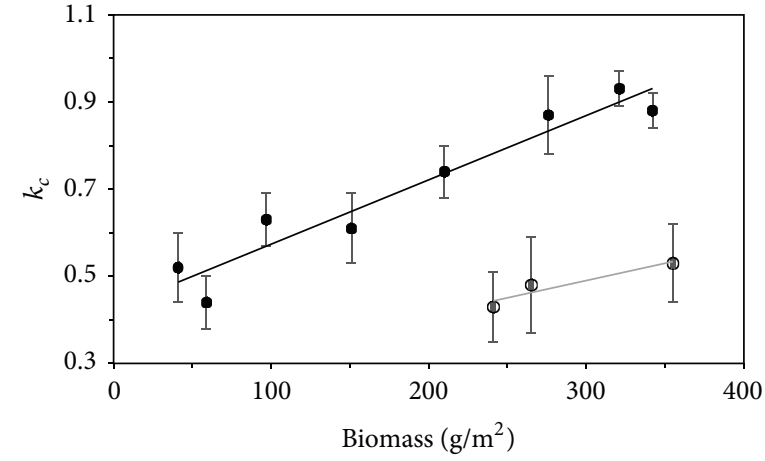

(b)

FIGURE 5: (a) The seasonal variation of biomass in this swamp meadow ecosystem in 2004 and (b) the response of $k_{c}$ to biomass. The $k_{c}$ was averaged with a bin width of $50 \mathrm{~g} / \mathrm{m}^{2}$ for biomass. Bars indicate mean \pm SD.

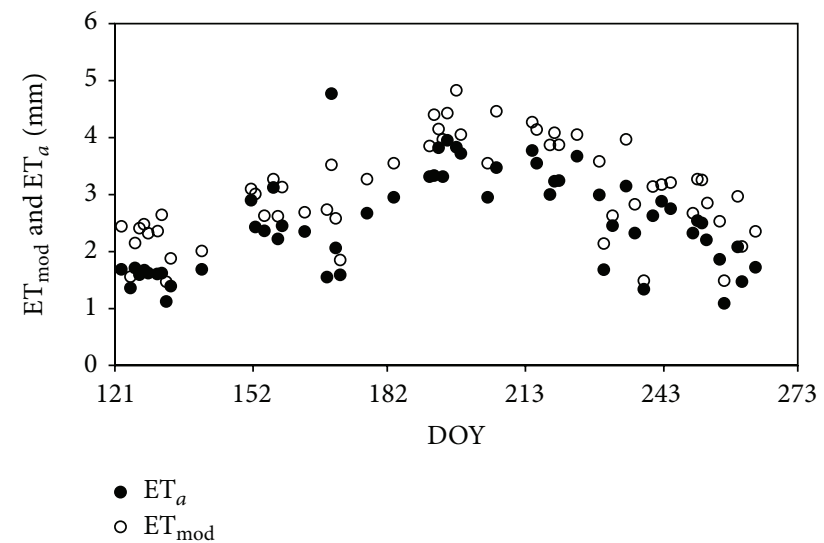

FIGURE 6: Seasonal variation in the measured and simulated ET (ET and $\mathrm{ET}_{\text {mod }}$ ) for days without rain in 2005 using (9).

TABLE 2: The validation statistics of the model simulated by the meteorological factors versus the model simulated by the meteorological factors and biotic factors.

\begin{tabular}{lccccc}
\hline & Slope & $R^{2}$ & RRMSE & IA & CD \\
\hline ET $_{\text {mod1 }}$ & 0.89 & 0.68 & 0.28 & 0.87 & 0.76 \\
ET $_{\text {mod2 }}$ & 0.95 & 0.76 & 0.23 & 0.93 & 0.87
\end{tabular}

$\mathrm{ET}_{\text {mod1 } 1}$ is simulated by the meteorological factors (VPD, $R_{n}$, and $\left.T_{a}\right) ; \mathrm{ET}_{\bmod 2}$ is simulated by these meteorological factors and biomass.

\section{Conclusions}

The FAO-Penman-Monteith model was used to simulate ET over the swamp meadow on the Sanjiangyuan Region. The reference ET was estimated by the FAO-P-M model and showed difference from the actual ET measured by the EC system. The crop coefficients $\left(k_{c}\right)$ were used to estimate $\mathrm{ET}_{a}$. The average value of $k_{c}$ during growing season was 0.55 (ranging from 0.30 to 0.92 ). VPD, $R_{n}$, and $T_{a}$ explained the majority of the daily variation in $k_{c}$, which showed a linear increase with an increase in $R_{n}$ and $T_{a}$ and a linear decrease with an increase in VPD. We also considered the impact of biomass on $k_{c}$, which showed a significant positive effect on $k_{c}$. A daily empirical $k_{c}$ model driven by VPD, $R_{n}, T_{a}$, and biomass was developed to estimate daily actual ET using the FAO-56 $k_{c}$ approach and the P-M model for reference ET. This ET model was validated against 2005 growing season data for this meadow and demonstrated a suitable and consistent performance between the simulated and measured ET.

\section{Conflict of Interests}

The authors declare that there is no conflict of interests regarding the publication of this paper.

\section{Acknowledgments}

This study was supported by the National Natural Science Foundation of China (31070433) and the Japan-China Research Cooperative Program (2010DFA31290).

\section{References}

[1] R. Burman and L. O. Pochop, "Evaporation, evapotranspiration and climatic data," Development in Atmospheric Science, vol. 22, pp. 1-5, 1994.

[2] T. Oki and S. Kanae, "Global hydrological cycles and world water resources," Science, vol. 313, no. 5790, pp. 1068-1072, 2006.

[3] N. K. Tyagi, D. K. Sharma, and S. K. Luthra, "Determination of evapotranspiration and crop coefficients of rice and sunflower with lysimeter," Agricultural Water Management, vol. 45, no. 1, pp. 41-54, 2000.

[4] L. B. Gong, C.-Y. Xu, D. L. Chen, S. Halldin, and Y. D. Chen, "Sensitivity of the Penman-Monteith reference evapotranspiration to key climatic variables in the Changjiang (Yangtze River) basin," Journal of Hydrology, vol. 329, no. 3-4, pp. 620-629, 2006.

[5] D. S. Torriani, P. Calanca, S. Schmid, M. Beniston, and J. Fuhrer, "Potential effects of changes in mean climate and climate variability on the yield of winter and spring crops in Switzerland," Climate Research, vol. 34, no. 1, pp. 59-69, 2007.

[6] C. H. B. Priestley and R. J. Taylor, "On the assessment of surface heat flux and evaporation using large-scale parameters," Monthly Weather Review, vol. 100, no. 2, pp. 81-92, 1972. 
[7] J. L. Monteith and M. H. Unsworth, Principles of Environmental Physics, Chapman and Hall, New York, NY, USA, 2nd edition, 1990.

[8] A. B. Frank, "Evapotranspiration from northern semiarid grasslands," Agronomy Journal, vol. 95, no. 6, pp. 1504-1509, 2003.

[9] S.-G. Li, C.-T. Lai, G. Lee et al., "Evapotranspiration from a wet temperate grassland and its sensitivity to micro-environmental variables," Hydrological Processes, vol. 19, no. 2, pp. 517-532, 2005.

[10] R. G. Allen, L. S. Pereira, D. Raes, and M. Smith, “Crop evapotranspiration, guidelines for computing crop water requirements," FAO Irrigation and Drainage Paper 56, FAO, Rome, Italy, 1998.

[11] L. E. Williams and J. E. Ayars, "Grapevine water use and the crop coefficient are linear functions of the shaded area measured beneath the canopy," Agricultural and Forest Meteorology, vol. 132, no. 3-4, pp. 201-211, 2005.

[12] J. G. Lockwood, "Is potential evapotranspiration and its relationship with actual evapotranspiration sensitive to elevated atmospheric $\mathrm{CO}_{2}$ levels?" Climatic Change, vol. 41, no. 2, pp. 193-212, 1999.

[13] F. L. Yang and G. S. Zhou, "Characteristics and modeling of evapotranspiration over a temperate desert steppe in Inner Mongolia, China," Journal of Hydrology, vol. 396, no. 1-2, pp. 139-147, 2011.

[14] D. Zheng, Q. S. Zhang, and S. H. Wu, Mountain Geoecology and Sustainable Development of the Tibetan Plateau, Kluwer Academic, Dordrecht, The Netherlands, 2000.

[15] X. F. Cui and H. F. Graf, "Recent land cover changes on the Tibetan Plateau: a review," Climatic Change, vol. 94, no. 1-2, pp. 47-61, 2009.

[16] J. Li, S. Jiang, B. Wang et al., "Evapotranspiration and its energy exchange in alpine meadow ecosystem on the Qinghai-Tibetan Plateau," Journal of Integrative Agriculture, vol. 12, no. 8, pp. 1396-1401, 2013.

[17] S. Alexandris and P. Kerkides, "New empirical formula for hourly estimations of reference evapotranspiration," Agricultural Water Management, vol. 60, no. 3, pp. 157-180, 2003.

[18] J. Cai, Y. Liu, T. W. Lei, and L. S. Pereira, "Estimating reference evapotranspiration with the FAO Penman-Monteith equation using daily weather forecast messages," Agricultural and Forest Meteorology, vol. 145, no. 1-2, pp. 22-35, 2007.

[19] D. M. Sumner and J. M. Jacobs, "Utility of Penman-Monteith, Priestley-Taylor, reference evapotranspiration, and pan evaporation methods to estimate pasture evapotranspiration," Journal of Hydrology, vol. 308, no. 1-4, pp. 81-104, 2005.

[20] L. A. Wever, L. B. Flanagan, and P. J. Carlson, "Seasonal and interannual variation in evapotranspiration, energy balance and surface conductance in a northern temperate grassland," Agricultural and Forest Meteorology, vol. 112, no. 1, pp. 31-49, 2002.

[21] A. Hammerle, A. Haslwanter, U. Tappeiner, A. Cernusca, and G. Wohlfahrt, "Leaf area controls on energy partitioning of a temperate mountain grassland," Biogeosciences, vol. 5, no. 2, pp. 421-431, 2008.

[22] X. C. Zhang, S. Gu, X. Q. Zhao et al., "Radiation partitioning and its relation to environmental factors above a meadow ecosystem on the Qinghai-Tibetan Plateau," Journal of Geophysical Research: Atmospheres, vol. 115, no. 10, Article ID D10106, 2010.

[23] D. Baldocchi and T. Meyers, "On using eco-physiological, micrometeorological and biogeochemical theory to evaluate carbon dioxide, water vapor and trace gas fluxes over vegetation: a perspective," Agricultural and Forest Meteorology, vol. 90, no. 1-2, pp. 1-25, 1998.

[24] S. Gu, Y. H. Tang, X. Y. Cui et al., "Characterizing evapotranspiration over a meadow ecosystem on the Qinghai-Tibetan Plateau," Journal of Geophysical Research: Atmospheres, vol. 113, no. D8, 2008.

[25] E. Kellner, "Surface energy fluxes and control of evapotranspiration from a Swedish Sphagnum mire," Agricultural and Forest Meteorology, vol. 110, no. 2, pp. 101-123, 2001.

[26] Y. Hao, Y. Wang, X. Huang et al., "Seasonal and interannual variation in water vapor and energy exchange over a typical steppe in Inner Mongolia, China," Agricultural and Forest Meteorology, vol. 146, no. 1-2, pp. 57-69, 2007.

[27] G. Dong, J. Guo, J. Chen et al., "Effects of spring drought on carbon sequestration, evapotranspiration and water use efficiency in the songnen meadow steppe in northeast China," Ecohydrology, vol. 4, no. 2, pp. 211-224, 2011.

[28] H. X. Miao, S. P. Chen, J. Q. Chen et al., "Cultivation and grazing altered evapotranspiration and dynamics in Inner Mongolia steppes," Agricultural and Forest Meteorology, vol. 149, no. 11, pp. 1810-1819, 2009.

[29] L. Zhou and G. S. Zhou, "Measurement and modelling of evapotranspiration over a reed (Phragmites australis) marsh in Northeast China," Journal of Hydrology, vol. 372, no. 1-4, pp. 4147, 2009.

[30] L. E. Williams, C. J. Phene, D. W. Grimes, and T. J. Trout, "Water use of mature Thompson Seedless grapevines in California," Irrigation Science, vol. 22, no. 1, pp. 11-18, 2003.

[31] G. A. de Medeiros, F. B. Arruda, and E. Sakai, "Crop coefficient for irrigated beans derived using three reference evaporation methods," Agricultural and Forest Meteorology, vol. 135, no. 14, pp. 135-143, 2005. 

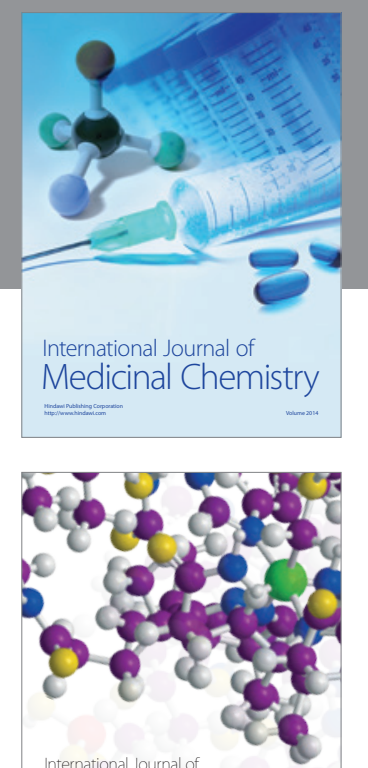

\section{Carbohydrate} Chemistry

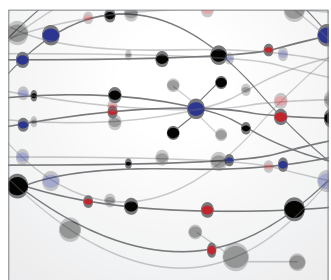

The Scientific World Journal
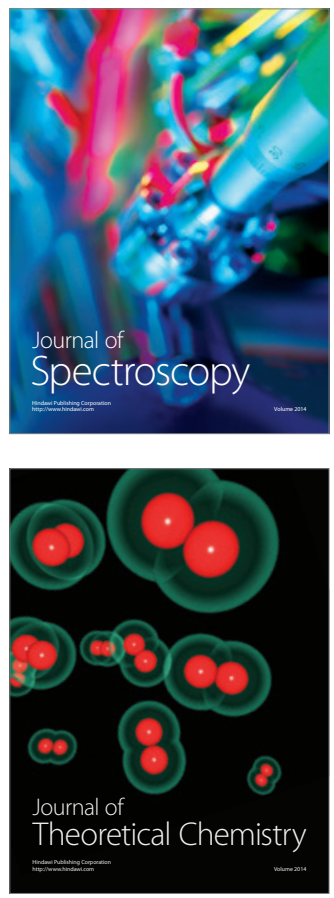
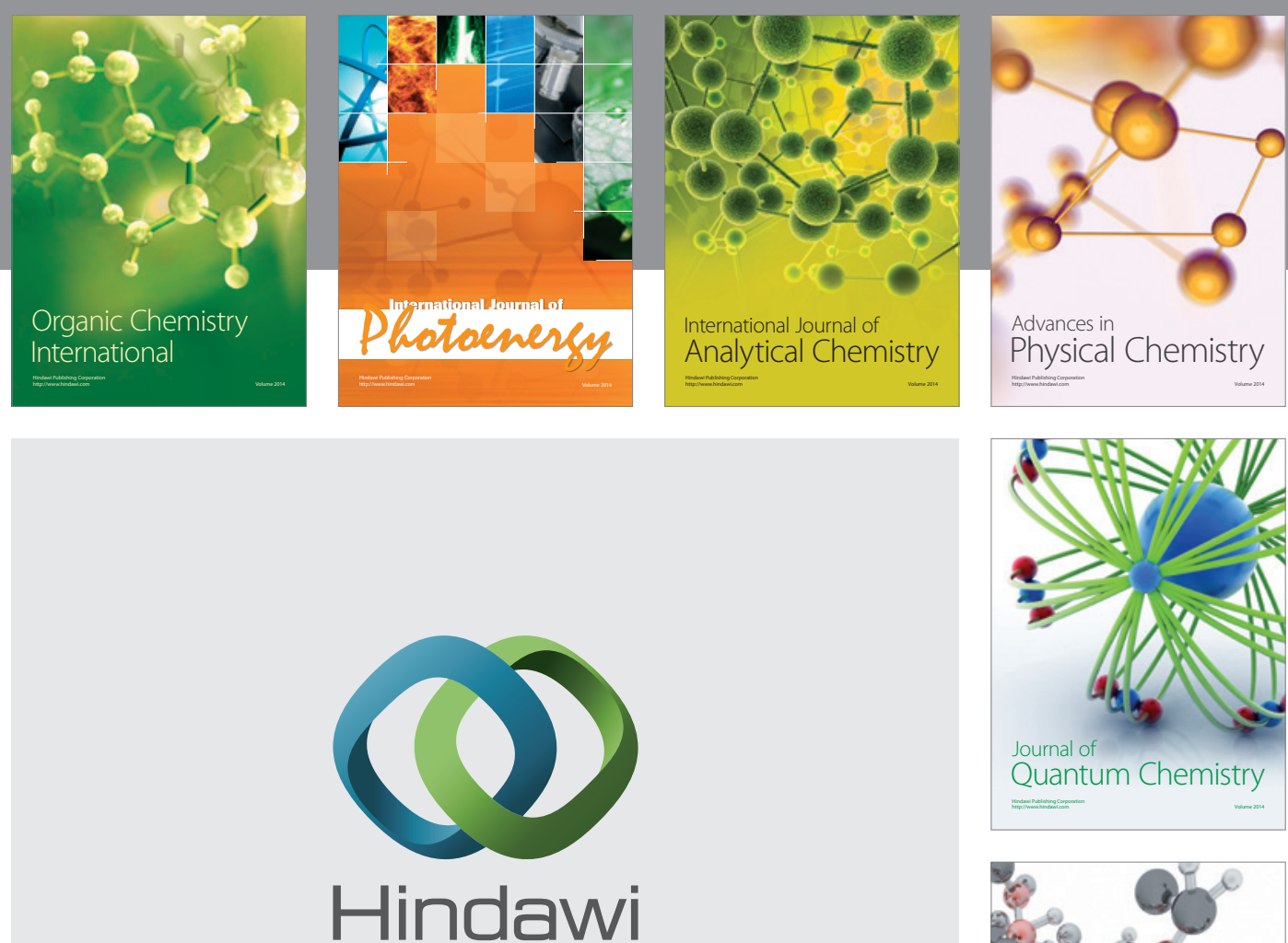

Submit your manuscripts at

http://www.hindawi.com

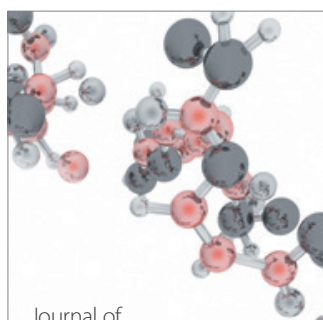

Analytical Methods

in Chemistry

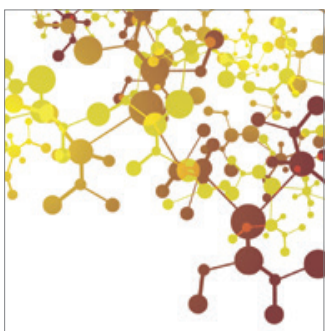

Journal of

Applied Chemistry

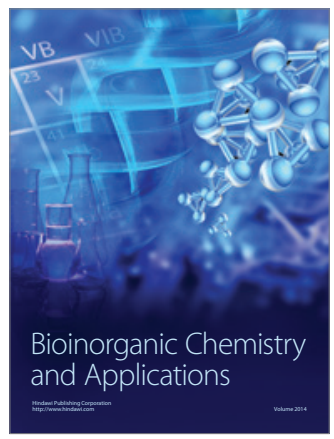

Inorganic Chemistry
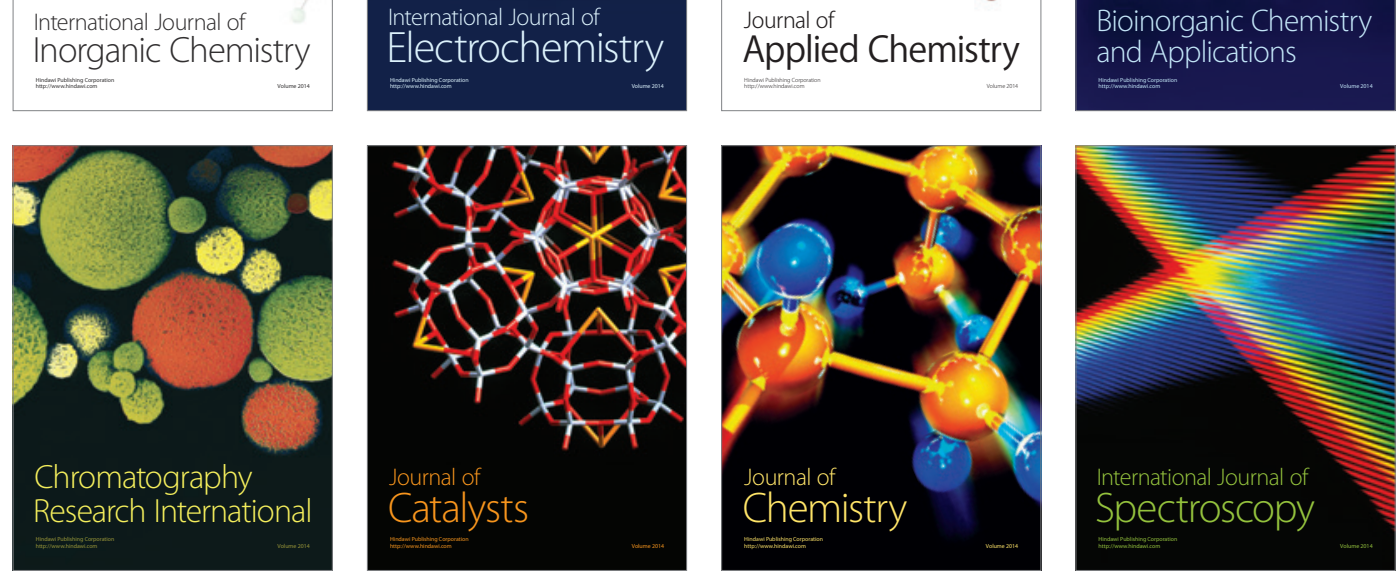